\title{
17. MAGNETIC PROPERTIES OF BASEMENT ROCKS, LEG 37, SITE 332
}

\author{
U. Bleil, Institut für Geophysik, Ruhr-Universität Bochum, West Germany \\ and \\ N. Petersen, Institut für Geophysik, Universität Munchen, West Germany
}

\section{INTRODUCTION}

Sixty-two (21 semioriented, 41 nonoriented) samples from Holes $332 \mathrm{~A}$ and $332 \mathrm{~B}$ were analyzed for paleomagnetic and rock magnetic properties. At least one sample was available from most of the cores. Chemical and, in part, mineral compositions were obtained on the same samples by Flower et al. (this volume). Some of their results have been incorporated for comparison with data from the ore minerals.

Although routine paleomagnetic work was done for all samples, the main emphasis was on a detailed study of the magnetic mineral components. The aim of these measurements is an identification of the ferrimagnetic phases, in particular of their oxidation state. The effects of alteration on magnetic properties of the ore minerals are discussed.

\section{PALEOMAGNETIC MEASUREMENTS}

\section{Methods}

For the conventional paleomagnetic study of the samples, intensities $(J)$ and directions $(I, D)$ of natural remanent magnetism (NRM) were measured on a Digico Spinner Magnetometer. The samples were cylinders, about $2.4 \mathrm{~cm}$ long and with a diameter of 2.2 (Hole 332A) and $2.5 \mathrm{~cm}$ (Hole 332B). For the semioriented samples only the inclination $(I)$ of remanence could be determined as the orientation of the core is limited to the vertical direction. The variation of the declination $(D)$ of remanence was measured relative to a fiducial azimuthal mark. For the nonoriented samples, measurements of remanence were also related to an arbitrary marking.

A systematic alternating-field (AF) demagnetization treatment was carried out in a field-compensated space using a two-axis tumbler device. The NRM of seven pilot samples from each hole was measured after every stage of a detailed stepwise demagnetization in fields of $0,25,50,75,100,150,200,250,300,400,500,600,800$, 1000, 2000 oe. For all remaining samples a routine demagnetization was performed in $0,25,50,100,200$, 500 oe fields. The volume susceptibility was measured with a Bison magnetic susceptibility bridge. Isothermal saturation remanent magnetizations $\left(J_{\mathrm{SR}}\right)$ were produced in a $10^{4}$ oe field. The bulk coercitivity $\left(H_{\mathrm{C}}\right)$ and the coercitivity of remanence $\left(H_{\mathrm{CR}}\right)$ were determined by a progressive reduction of this remanence with magnetic d.c. fields applied in opposite direction.

\section{Results}

The results of paleomagnetic and bulk rock magnetic measurements are listed in Table 11, Chapter 2 (this volume). Figures $1 \mathrm{a}$ and $\mathrm{b}$ show downhole plots of the NRM, the susceptibility, the Königsberger ratio, and the medium destructive field.

\section{Discussion}

\section{Remanent Magnetization}

The NRM intensity varies widely in both holes: $0.4-$ $20 \times 10^{-3} \mathrm{emu} / \mathrm{cc}$ in $332 \mathrm{~A}$ and $0.25-10 \times 10^{-3} \mathrm{emu} / \mathrm{cc}$ in $332 \mathrm{~B}$. As for most magnetic properties, there is no apparent downhole trend in the NRM intensity. Systematic variations characteristic of single cooling units (Watkins and Haggerty, 1967; Marshall and Cox, 1972; Petersen, 1976) were not found presumably due to the lack in continuous sampling. The mean (arithmetic) NRM intensity values are $(3.325 \pm 3.373)$ $\times 10^{-3} \mathrm{emu} / \mathrm{cc}$ for Hole $332 \mathrm{~A}$ and $(2.803 \pm 2.604) \times$ $10^{-3} \mathrm{emu} / \mathrm{cc}$ for Hole 332B (equal weight given to each sample). These values are substantially lower than the averages found for dredged oceanic basalts, but are quite similar to other DSDP data as summarized by Lowrie (1974).

\section{Magnetic Stability (Intensity)}

The following two parameters are used to describe the magnetic stability: the medium destructive field (MDF) and $S_{200}=J_{200} / J_{\mathrm{NRM}}$ the ratio between the NRM intensity after AF-demagnetization in a 200-oe field and the original NRM intensity. A significant correlation was found between these two parameters and the bulk coercitivity and the coercitivity of remanence in both holes. The mean MDF of Hole 332A, $374 \pm 142$ oe, is distinctly higher than the $266 \pm 141$ oe observed for Hole 332B. Both values fall into the range reported for other DSDP samples (Lowrie, 1974). These stabilities are high compared to subaerial basalts, reflecting the generally small grain size of ore minerals in ocean floor basalts. In Figure 2 AF-demagnetization curves are shown for some representative samples that are used for a classification (see Table 11, Chapter 2, this volume).

\section{Magnetic Stability (Directions)}

The NRM directions measured are generally similar to those reported for these sites by Ade-Hall et al. (1975). A main feature is the abundance of relatively shallow inclinations as compared to a central dipole 
field for the area $\left(56^{\circ}\right)$. In most cases there is only negligible change of these unusual inclinations during AF-demagnetization; especially no general trend to steeper inclinations was observed. Vector diagram plots (Zijderfeld, 1966) of the horizontal and vertical magnetization component were used to define a stable inclination value.

AF-demagnetization curve types indicating the presence of additional antiparallel softer remanent components (denoted with one or two asterisks, respectively) are abundant in both holes (Table 11, Chapter 2, this volume). They are of special interest regarding the acquisition of secondary remanences. The type $\left({ }^{*}\right)$ is interpreted as a superposition of two antiparallel components, whereas in type $\left({ }^{* *}\right)$ at least three different magnetizations must contribute. Type $\left(^{*}\right)$ occurs for both normal and reversed remanences; type (**) was only identified for samples carrying a normal magnetization. We argue, therefore, that the secondary components were not only formed during the last $7 \cdot 10^{5} \mathrm{yr}$ of normal Brunhes epoch but also during earlier epochs of reversed polarity. Assuming that the secondary magnetic components reflect an earth magnetic field direction and not intrinsic properties of the magnetic mineral phases like partial self-reversal (Creer and Petersen, 1969; Petersen and Bleil, 1973), we have to resort to a build-up at elevated temperatures or during maghemitization (Butler, 1973). This conclusion is based on two assumptions: (a) a negative secondary component in samples showing a positive overall magnetization must apparently have a higher stability than any viscous remanence acquired during the present field epoch, and (b) a roughly equal length of normal and reversed polarity in the last 3.5 m.y.

\section{Susceptibility}

Downhole variation of susceptibility in Hole $332 \mathrm{~A}$ is much more-restricted than in Hole 332B (Figures 1a, 1b). A moderate but significant negative correlation exists between susceptibility and the various stability parameters which may be interpreted in terms of grain size variations (see Table 1). In contrast, no correlations were found for susceptibility and NRM intensity.

Königsberger ratios $(Q)$ derived from the susceptibility values vary between 1.3 and 157 ; because about $75 \%$ of the $Q$ values are higher than 10 , induced magnetizations of the rock sequence penetrated at Site 332 will not contribute significantly to the measured anomalies.

\section{ROCK MAGNETIC MEASUREMENTS}

\section{Methods}

Rock magnetic analysis was done on 10 samples from Hole 332A and 12 samples from Hole 332B. These studies comprise ore microscopic observation including measurement of modal abundance and grain size of the

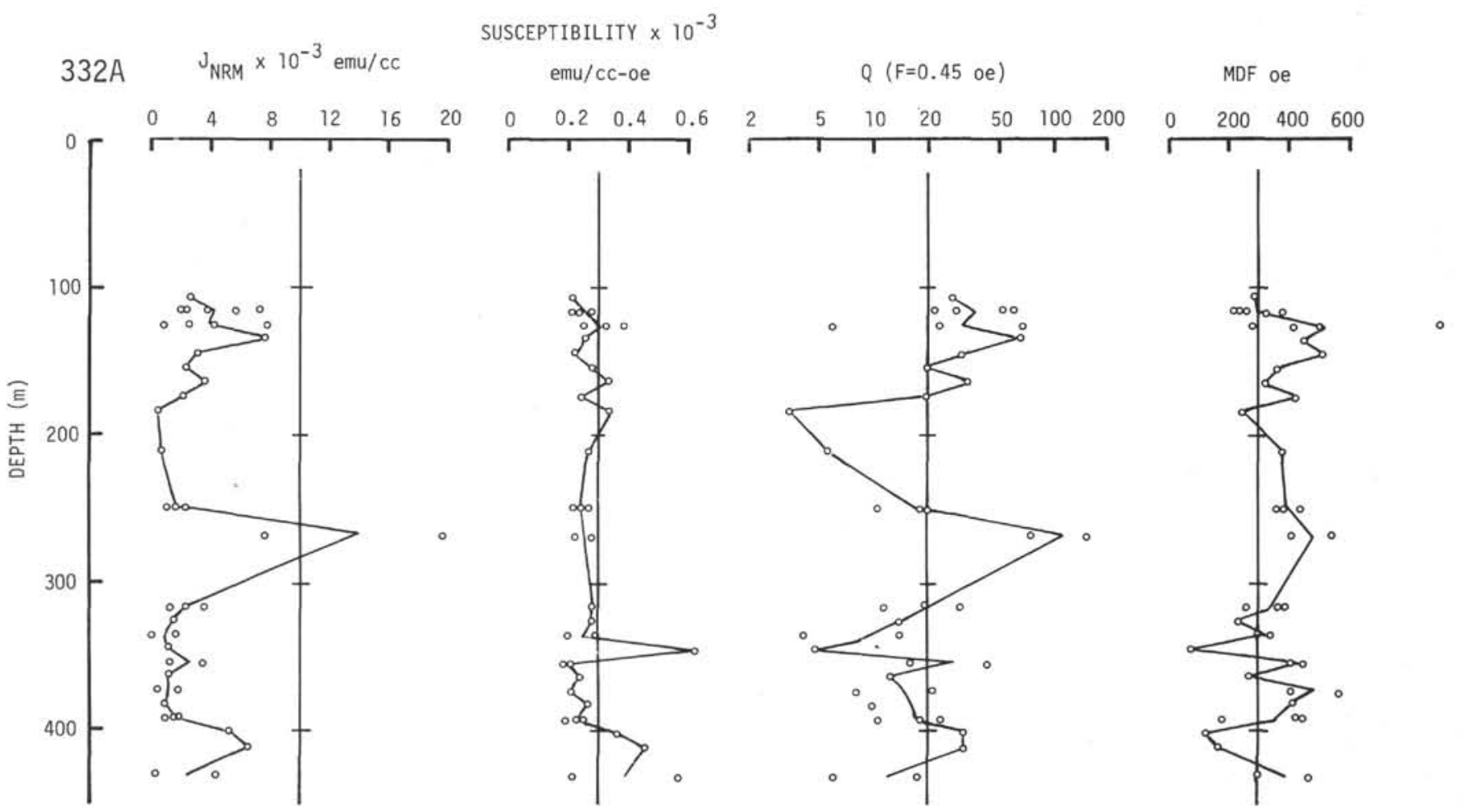

Figure 1a. Downhole variation of the intensity of natural remanent magnetization (NRM), the volume susceptibility, the $K \ddot{n}$ igsberger ratio $Q$ calculated for a magnetic field of 0.45 oe at the drilling sites and the medium destructive field (MDF). Results of several samples from the same core are shown at identical depths. Mean values of individual cores are connected by solid lines. Hole 332A. 


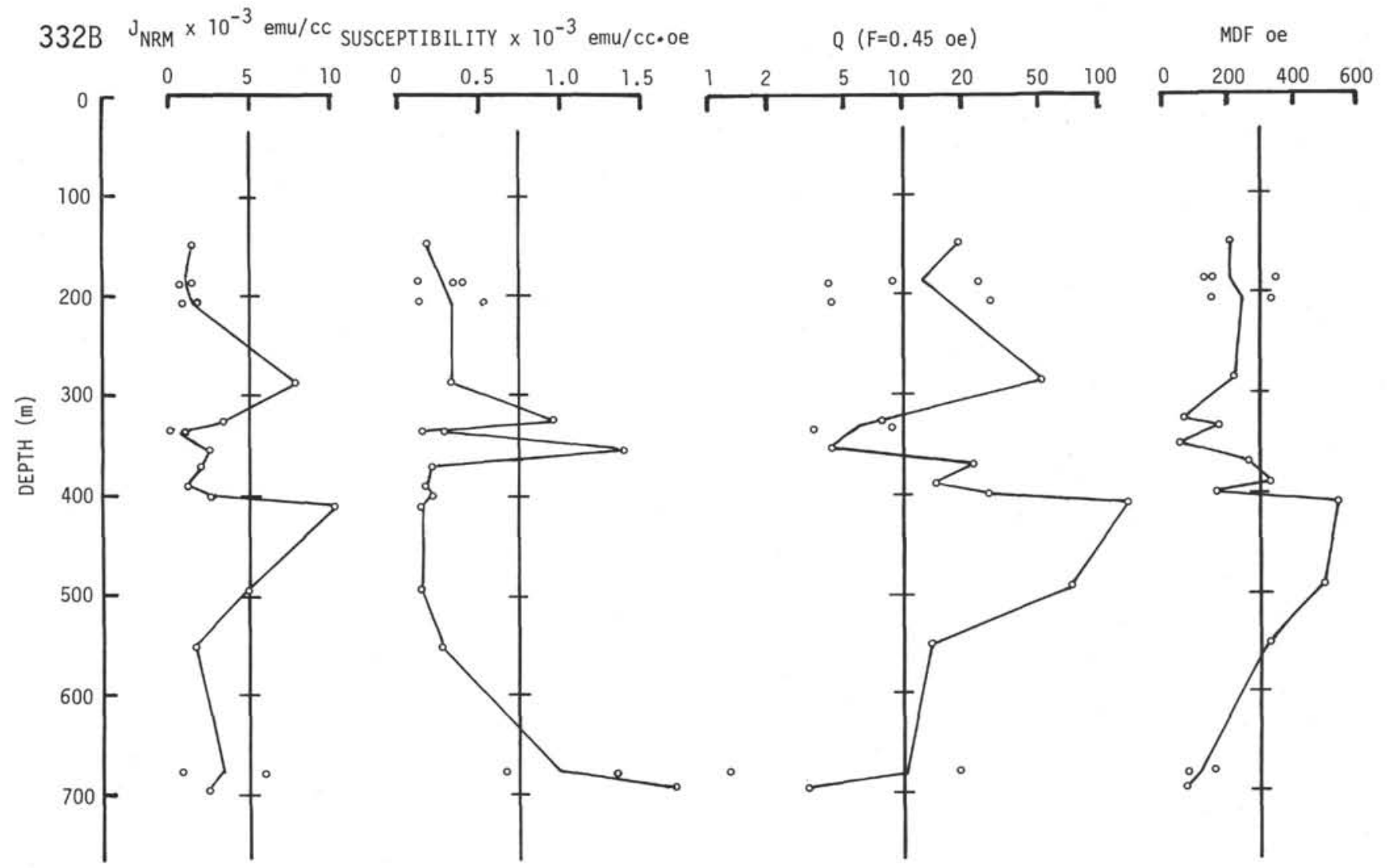

Figure 1b. Downhole variation of the intensity of natural remanent magnetization (NRM), the volume susceptibility, the $K$ önisberger ratio $Q$ calculated for a magnetic field of 0.45 oe at the drilling sites and the medium destructive field $(M D F)$. Results of several samples from the same core are shown at identical depths. Mean values of individual cores are connected by solid lines. Hole 332B.

opaque mineral phases, determination of the lattice constant of the ferrimagnetic Fe-Ti spinels, and microprobe chemical analysis (the latter only on two samples from each hole). Furthermore Curie temperatures, saturation magnetization, and the different proportions of ferrimagnetism, paramagnetism, and superparamagnetism were determined by means of a translation balance.

\section{Optical and X-ray Measurements}

Polished sections were studied under reflected light using a Leitz microscope. Volume content of the opaque phases and their mean grain size were measured on a Quantimet image analyzing device. Conventional point counting was also done on some samples for comparison. The results deviate systematically, point counting typically giving values higher by a factor of 1.5-2.5 compared to Quantimet data, depending on the total number of grains analyzed per unit area.

Lattice constants of the magnetically separated $\mathrm{Fe}-\mathrm{Ti}$ spinels were determined using the conventional DebyeScherrer technique.

\section{Strong Field Magnetic Measurements}

A translation balance was used for those measurements, where magnetic fields up to 13,000 oe could be applied. Magnetization was measured in the temperature range between $-180^{\circ} \mathrm{C}$ and $+700^{\circ} \mathrm{C}$, the samples being in air. For the Curie temperature measurements a magnetic field of 4250 oe was chosen to reduce the influence of paramagnetism. In order to determine the Neel $J S(T)$ curve type of the Fe-Ti spinel phase, the temperature dependence of magnetization was measured in a field of 10,100 oe. In this case (Figure 3), the paramagnetism of the silicates has to be taken into account. An apparent paramagnetic susceptibility was determined from the linear field dependence of magnetization, obtained after saturation of the ferrimagnetic mineral component and measured at constant temperatures. The $J_{S}(T)$ curve of the ferrimagnetic phase was then derived by subtraction of the apparent paramagnetism from the bulk magnetization curve.

The temperature dependence of the reciprocal apparent paramagnetic susceptibility thus determined is nonlinear, showing that other contributions to the magnetization exist. As known from the petrographic analysis, antiferromagnetic components cannot be the cause for this nonlinearity. We assume therefore, that superparamagnetism of very fine-grained Fe-Ti oxides is responsible.

This hypothetical superparamagnetism has been determined quantitatively by subtraction of the true paramagnetism from the apparent paramagnetism. The former was measured at $700^{\circ} \mathrm{C}$, thus being well above the Curie temperature of any ferrimagnetic phase. A 


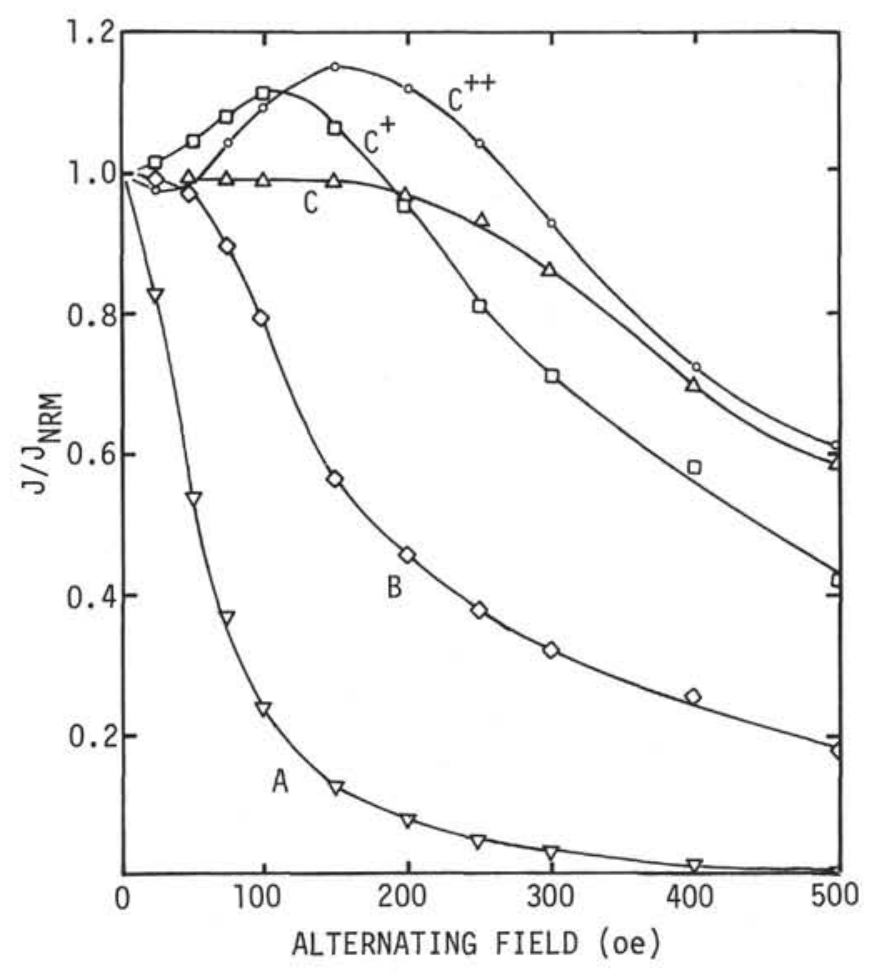

Figure 2. Alternating-field demagnetization curves. Letter symbols indicate different types of magnetic stability, crosses the presence of antiparallel magnetic components (see text). $\Delta$ : Hole 332B, Sample 10-3, 39-41 cm (\#2A); $\diamond:$ Hole 332B, Sample 9-1, 88-90 cm (\#10); $\Delta$ : Hole 332A, Sample 23-1, 130-132 cm (\#18); ㅁ: Hole 332A, Sample 36-1, 21-23 cm (\#3); 0: Hole 332A, Sample 34-2, 36-38 $\mathrm{cm}(\# 5)$.

detailed discussion of this method shall be given elsewhere.

Results

\section{Ore Microscopic Investigation}

The main opaque minerals are titanomagnetites with minor iron sulfides. The mean modal opaque content is $1.0 \mathrm{vol} \%$, distinctly lower than for an average subaerial basalt. The volume of iron sulfides is always less than $10 \%$ of the titanomagnetite phase (highest values were found in Core 44 of Hole 332B) and therefore should not contribute significantly to the magnetization of the rocks.

Titanomagnetite, the main carrier of remanent magnetization, is maghemized to a variable extent, a clear indication for low temperature oxidation (oxidation temperatures below $250^{\circ} \mathrm{C}$ ). In all samples so far studied no sign of high temperature deuteric oxidation was found. Also, neither primary nor secondary ilmenite was observed. With few exceptions the grain sizes of titanomagnetite are much smaller than in subaerial basalts, average grain size for the Hole 332A rocks being $4.7 \mu \mathrm{m}$ and for Hole 332B rocks $5.7 \mu \mathrm{m}$. These results are in good agreement with data published by Lowrie et al. (1972). The small grain size and the frequent occurrence of skeletal-shaped titanomag- netite grains are indications for rapid cooling of relatively small rock units.

\section{Curie Temperatures and Lattice Constants}

Both parameters are listed in Table 1 , and their downhole variation is shown in Figure $4 a, b$. Curie temperature and lattice constant vary between $237^{\circ} \mathrm{C}$ to $343^{\circ} \mathrm{C}$ and $8.369 \AA$ to $8.427 \AA$, respectively, in Hole $332 \mathrm{~A}$ and between $150^{\circ} \mathrm{C}$ to $467^{\circ} \mathrm{C}$ and $8.358 \AA$ to $8.464 \AA$ in Hole $332 \mathrm{~B}$. A striking negative correlation exists between both these parameters. None of the analyzed rocks contain stoichiometric titanomagnetites when compared with values measured for synthetic stoichiometric titanomagnetites (Bleil, 1976) and taking into account the influence of impurity ions like $\mathrm{Al}$ and $\mathrm{Mg}$ (Table 2). In accordance with the ore microscopic observations, we find variable degrees of alteration of the titanomagnetites resulting most likely from halmyrolysis (Hart, 1973).

In order to determine quantitatively the oxidation state defined by the oxidation parameter $z$ (O'Reilly and Banerjee, 1967) the Readman and O'Reilly (1970) $T c-a_{o}$ contour lines have been used. Both parameters were corrected for the $\mathrm{Al}$ and $\mathrm{Mg}$ impurity ions according to Richards et al. (1973). These corrections are based on the microprobe analysis listed in Table 3. For samples where no analysis was available the mean of these values was used. The compositions thus obtained are shown in the ternary system $\mathrm{FeO}-\mathrm{Fe}_{2} \mathrm{O}_{3}-\mathrm{TiO}_{2}$ in Figure $5 \mathrm{a}, \mathrm{b}$. Also shown are the corresponding wholerock compositions determined by Flower et al. (this volume).

From these figures it can be seen that the ore component in most of the rocks is highly oxidized. However, there is no apparent correlation between the oxidation state of the ore phase and the $\mathrm{Fe}^{2+} / \mathrm{Fe}^{3+}$ ratio of the whole rock. Therefore, it seems to us that in the deep ocean environment oxidation effects more rapidly the ore component than the silicate phases.

A downhole plot of the oxidation parameter $z$ (Figure $4 \mathrm{a}, \mathrm{b}$ ) shows a general trend of decreasing $z$ values with depth. However, in Hole 332B there are two significant breaks in this trend with very low oxidation at a depth of 350 meters (Core 10) and near 700 meters (Cores 44 and 46). The low $z$ values correlate with large grain sizes but not vice versa; larger grain size may indicate intrusive or thick extrusive bodies. These samples also show anomalous values for most other magnetic parameters (Figure $1 b$ ). The very high $z$ values observed between 400 and 550 meters in Hole 332B may tentatively be interpreted as (a) a noncontinuous magma emplacement; i.e., the rocks now below about 400 meters formed the uppermost part of the basement for a relatively long time, or (b) the rock sequence between 400 and 550 meters is highly fractured giving free access to seawater even at this depth.

Assuming that the magnetic ore grains have originally been stoichiometric titanomagnetites and that the original $\mathrm{Fe} / \mathrm{Ti}$ ratio has not significantly been changed by the oxidation process, the original composition-as expressed by the parameter $x$ (stoichiometric titanomagnetites having the chemical formula $\mathrm{Fe}_{3}-$ $\left.{ }_{x} \mathrm{Ti}_{\mathrm{x}} \mathrm{O}_{4}\right)$-can be determined from Figure 5 . The values thus obtained are listed in Table 1. The correlation 
TABLE 1

Rock Magnetic Data, Site 332

\begin{tabular}{|c|c|c|c|c|c|c|c|c|c|}
\hline $\begin{array}{c}\text { Sample } \\
\text { (Interval in } \mathrm{cm} \text { ) }\end{array}$ & $\begin{array}{l}\text { Depth } \\
\text { (m) }\end{array}$ & $T_{C}\left({ }^{\circ} \mathrm{C}\right)$ & $a_{O}(\AA)$ & $z$ & $x$ & $\begin{array}{l}\text { Initial Curie } \\
\text { Temperature } \\
\left({ }^{\circ} \mathrm{C}\right)\end{array}$ & $\begin{array}{c}\text { Vol } \% \\
\text { Ore }\end{array}$ & $\begin{array}{c}\text { Ore } \\
\text { Grain } \\
\text { Size }\end{array}$ & $\underset{(\mathrm{emu} / \mathrm{g})}{\mathrm{J} \mathrm{S}}$ \\
\hline \multicolumn{10}{|l|}{ Hole $332 \mathrm{~A}$} \\
\hline $\begin{array}{l}6-2,107-109(8) \\
8-1,50-52(6) \\
12-1,81-83(9) \\
17-1.50-52(6) \\
29-1,65-66(9) \\
30-1,135-137(20) \\
32-2,28-30(2) \\
36-1,21-23(3) \\
37-1,101-103(4) \\
40-3,35-37(4 A)\end{array}$ & $\begin{array}{l}104.57 \\
121.50 \\
159.81 \\
207.00 \\
321.15 \\
331.35 \\
350.78 \\
387.21 \\
397.51 \\
428.35\end{array}$ & $\begin{array}{l}343 \\
313 \\
273 \\
250 \\
247 \\
262 \\
271 \\
297 \\
237 \\
282\end{array}$ & $\begin{array}{l}8.378 \pm 0.002 \\
8.369 \pm 0.002 \\
8.388 \pm 0.003 \\
8.391 \pm 0.001 \\
8.406 \pm 0.002 \\
8.403 \pm 0.003 \\
8.425 \pm 0.02 \\
8.388 \pm 0.002 \\
8.427 \pm 0.001 \\
8.404 \pm 0.003\end{array}$ & $\begin{array}{l}0.80 \\
0.86 \\
0.79 \\
0.78 \\
0.71 \\
0.68 \\
0.53 \\
0.77 \\
0.56 \\
0.68\end{array}$ & $\begin{array}{l}0.57 \\
0.68 \\
0.69 \\
0.73 \\
0.67 \\
0.58 \\
0.53 \\
0.64 \\
0.58 \\
0.59\end{array}$ & $\begin{array}{r}147 \\
52 \\
43 \\
8 \\
57 \\
57 \\
106 \\
179 \\
87 \\
138 \\
129\end{array}$ & $\begin{array}{l}0.6 \\
1.3 \\
1.0 \\
1.1 \\
1.3 \\
1.4 \\
0.6 \\
1.0 \\
1.5 \\
0.4\end{array}$ & $\begin{array}{l}3.9 \\
3.0 \\
4.3 \\
4.8 \\
8.3 \\
5.7 \\
1.7 \\
2.9 \\
8.2 \\
4.4\end{array}$ & $\begin{array}{l}0.160 \\
0.245 \\
0.370 \\
0.274 \\
0.270 \\
0.276 \\
0.170 \\
0.285 \\
0.395 \\
0.160\end{array}$ \\
\hline \multicolumn{10}{|l|}{ Hole 332B } \\
\hline $\begin{array}{l}1-5,57-60(6) \\
2-4,122-125(13) \\
3-1,27-30(2 \mathrm{~B}) \\
6-1,111-114(12) \\
9-1,88-90(10) \\
10-3,39-41(2 \mathrm{~A}) \\
15-1,103-105(9) \\
16-2,63-65(8) \\
25-1,106-113(16) \\
31-1,116-119(9) \\
44-5,124-126(11) \\
46-2,58-61(3 \mathrm{~B})\end{array}$ & $\begin{array}{l}148.57 \\
180.10 \\
199.81 \\
287.83 \\
333.76 \\
354.39 \\
399.53 \\
410.13 \\
494.56 \\
551.66 \\
681.24 \\
695.08\end{array}$ & $\begin{array}{l}393 \\
467 \\
420 \\
253 \\
244 \\
150 \\
260 \\
328 \\
298 \\
293 \\
217 \\
210\end{array}$ & $\begin{array}{l}8.375 \pm 0.002 \\
8.358 \pm 0.002 \\
8.367 \pm 0.001 \\
8.400 \pm 0.003 \\
8.415 \pm 0.002 \\
8.464 \pm 0.002 \\
8.410 \pm 0.003 \\
8.366 \pm 0.001 \\
8.379 \pm 0.002 \\
8.377 \pm 0.001 \\
8.452 \pm 0.001 \\
8.453 \pm 0.001\end{array}$ & $\begin{array}{l}0.80 \\
0.85 \\
0.82 \\
0.74 \\
0.65 \\
0.31 \\
0.67 \\
0.87 \\
0.83 \\
0.84 \\
0.26 \\
0.32\end{array}$ & $\begin{array}{l}0.47 \\
0.38 \\
0.43 \\
0.69 \\
0.63 \\
0.63 \\
0.63 \\
0.67 \\
0.68 \\
0.70 \\
0.51 \\
0.54\end{array}$ & $\begin{array}{r}229 \\
299 \\
259 \\
46 \\
95 \\
125 \\
95 \\
61 \\
52 \\
35 \\
197 \\
187\end{array}$ & $\begin{array}{l}0.2 \\
0.2 \\
0.2 \\
1.2 \\
1.2 \\
1.6 \\
1.4 \\
0.3 \\
0.8 \\
1.3 \\
1.3 \\
1.7\end{array}$ & $\begin{array}{r}1.6 \\
2.2 \\
2.5 \\
2.9 \\
6.8 \\
11.5 \\
7.3 \\
0.8 \\
3.0 \\
10.1 \\
9.8 \\
10.2\end{array}$ & $\begin{array}{l}0.138 \\
0.118 \\
0.120 \\
0.225 \\
0.280 \\
0.585 \\
0.248 \\
0.120 \\
0.095 \\
0.045 \\
0.715 \\
0.790\end{array}$ \\
\hline
\end{tabular}

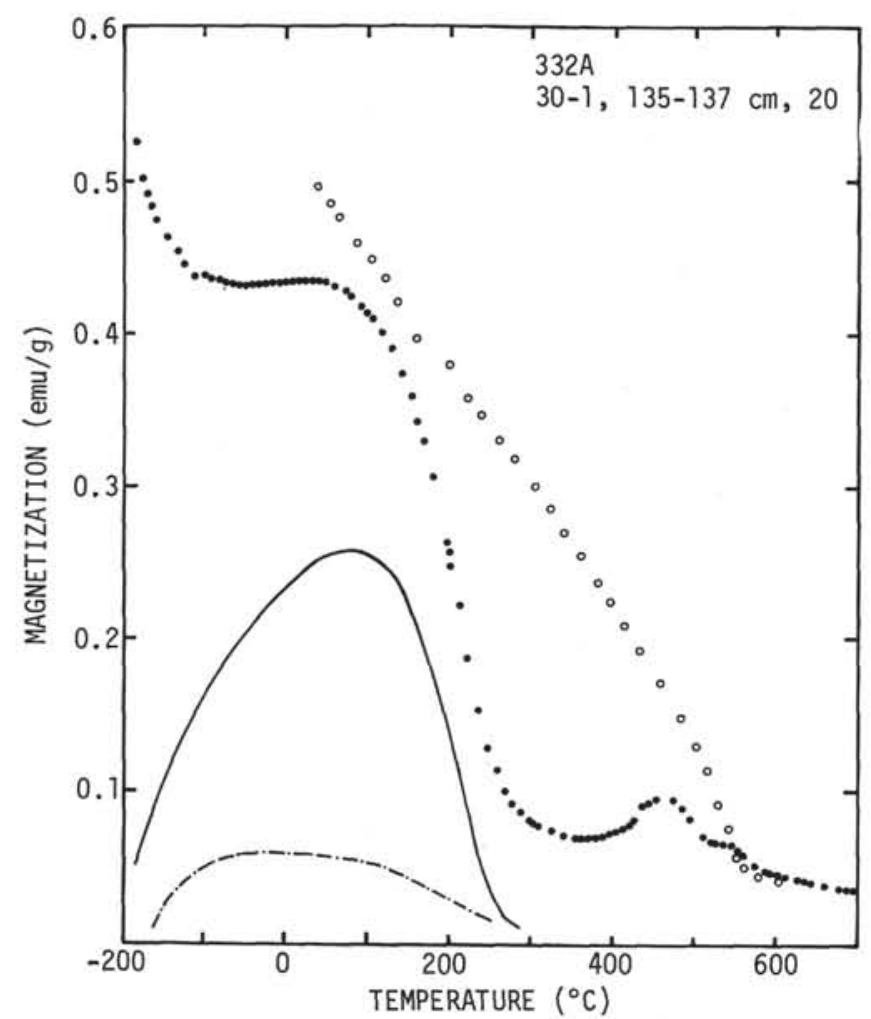

Figure 3. Example of thermomagnetic curve measured at 10,100 oe. Solid circles: total magnetization (heating); open circles: total magnetization (cooling). Solid curve: ferrimagnetic saturation magnetization; dash-dotted curve: superparamagnetic fraction. between the $\mathrm{TiO}_{2}$-content of the whole rock and the $x$ values of the titanomagnetites is poor (Figure 4). A direct correlation seems to exist only in the upper part of Hole 332B (Figure 4b). The variation of the $x$ values is remarkably small except for the uppermost and lowermost samples of Hole 332B.

The mean $x$ value of all samples $(0.60)$ is in very good agreement with the four microprobe analyses and also with other analyses from ocean floor basalts (Ozima et al., 1974).

A calculation of the initial Curie temperatures of the postulated primary titanomagnetites (being the carrier of the original thermoremanence acquired during primary cooling) gives values ranging between $8^{\circ} \mathrm{C}$ and $299^{\circ} \mathrm{C}$ (mean $T_{c i}: 119^{\circ} \mathrm{C}, 36 \%$ of the samples having a $T_{c i}$ below $60^{\circ} \mathrm{C}$, see Table 1). These values have been corrected for the $\mathrm{Al}$ and $\mathrm{Mg}$ impurities.

The abundance of low Curie temperatures makes it likely that partial remagnetization may have taken place at only moderately elevated temperatures. In this context it should be mentioned that the blocking temperature of most samples will be close to their Curie temperature, because of the generally very small grain size of the ore phase.

\section{Ferrimagnetism, Paramagnetism, and Superparamagnetism}

The $I_{s}(T)$ curves of the ferrimagnetic mineral phases investigated so far all show the shape of Neel P and $L$ type, which is also evidence for the presence of titanomagnetite (Schult, 1971).

There is a remarkably large contribution of the paramagnetic silicates to the total magnetization even 


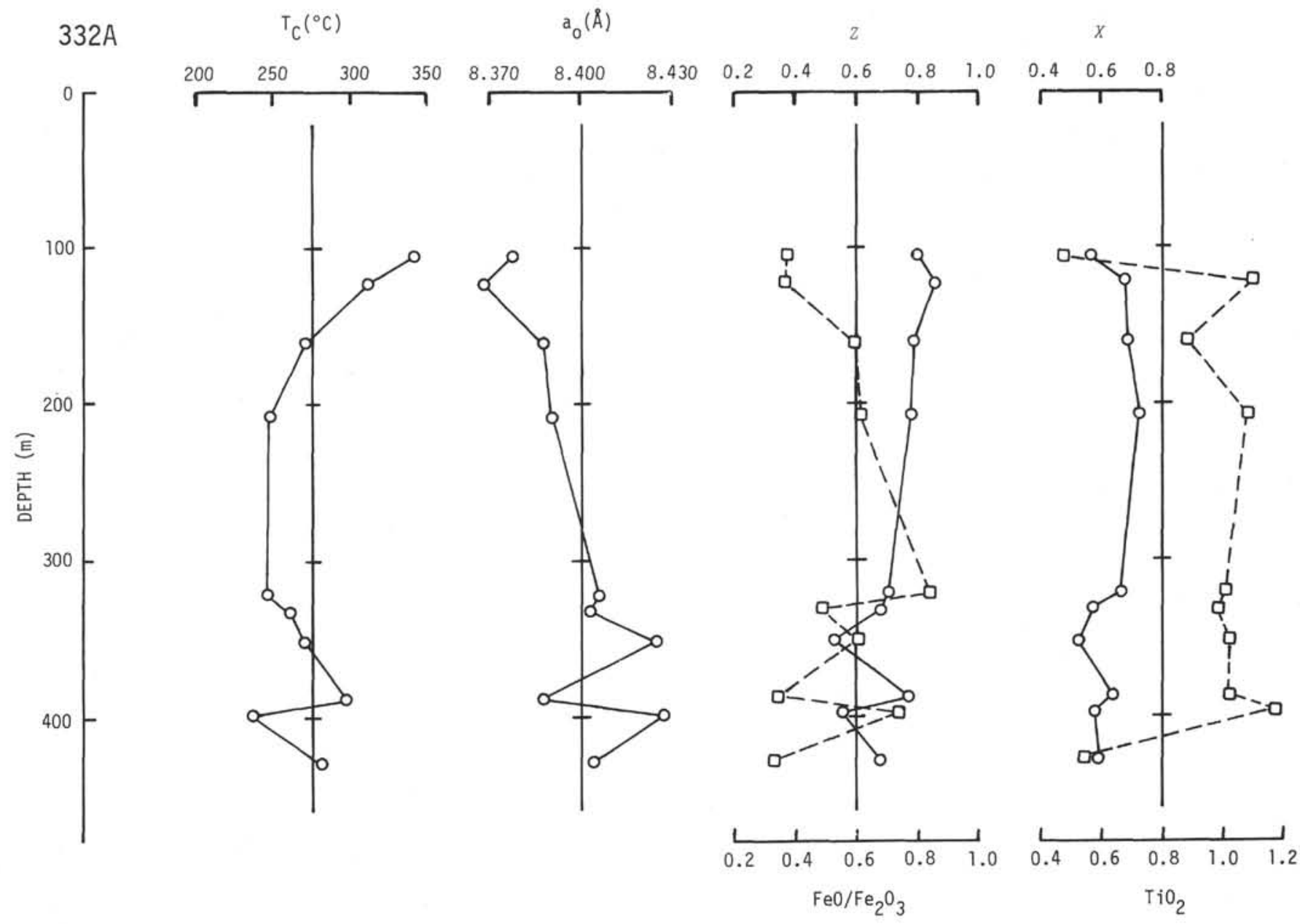

Figure 4a. Downhole variation of the Curie temperature and the lattice constant of the ferrimagnetic Fe-Ti spinel components, their oxidation parameter z together with the whole-rock $\mathrm{FeO} / \mathrm{Fe}_{2} \mathrm{O}_{3}$-ratio (dashed line) and the parameter $\mathrm{x}$ compared to the whole-rock titanium content (wt \%, dashed line). The parameter $\mathrm{z}$ gives the proportion of $\mathrm{Fe}^{2+}$ oxidized to $\mathrm{Fe}^{3+}$ in titanomagnetites, while $\mathrm{x}$ gives their titanium content.

at room temperature in strong magnetic fields: roughly $40 \%$ of the total magnetization measured at 10,100 oe are due to the paramagnetism of the silicates (Figure 3). In the basalts studied here only $10 \%$ of the total iron content of the rock is present as ore mineral as compared to about $50 \%$ in average subaerial basalts (Hargraves and Petersen, 1971). The former value is determined from a comparison of ore content and $\mathrm{Fe}$ content of the whole rock and independently from the thermomagnetic measurements.

All samples show an irreversible thermomagnetic curve characteristic of ocean floor basalts (Schaeffer and Schwarz, 1970). An example is shown in Figure 3. When heating the sample beyond $400^{\circ} \mathrm{C}$, a typical secondary maximum in magnetization is observed. This is generally interpreted as a decomposition of titanomaghemite into a nonmagnetic titanium-rich phase and a strongly magnetic titanium-poor spinel phase (O'Reilly and Readman, 1971). Because the temperature dependence of reciprocal strong field susceptibility is nonlinear, superparamagnetic effects are likely to contribute, amounting to about $20 \%$ of the saturation magnetization of the ferrimagnetic mineral phase at room temperature in a magnetic field of 10,100 oe. This indicates a fairly high content of very small ore grains which cannot be detected microscopically (these submicroscopic ore grains thus are not accounted for in the value of mean grain size given in Table 1).

\section{CONCLUSIONS}

At present we restrict our conclusions to a discussion of the NRM which is the most important parameter for an interpretation of marine magnetic anomaly patterns. Our data together with the results recently published by Ade-Hall et al. (1975) show that the nature of NRM of ocean floor basalts differs significantly from earlier assumptions used for interpretation and modeling of the anomaly pattern. The average NRM intensity is too low by at least a factor of 2 in order to fit the previously accepted model of a magnetic layer $2 \mathrm{~A}$ with a thickness of only 500 meters (Talwani et al., 1971). In addition, the presence of shallow inclinations and mixed polarities further complicates a simple magnetization model of the upper oceanic crust.

The following two arguments led us to the conclusion that the NRM of the rocks studied is of a composite 

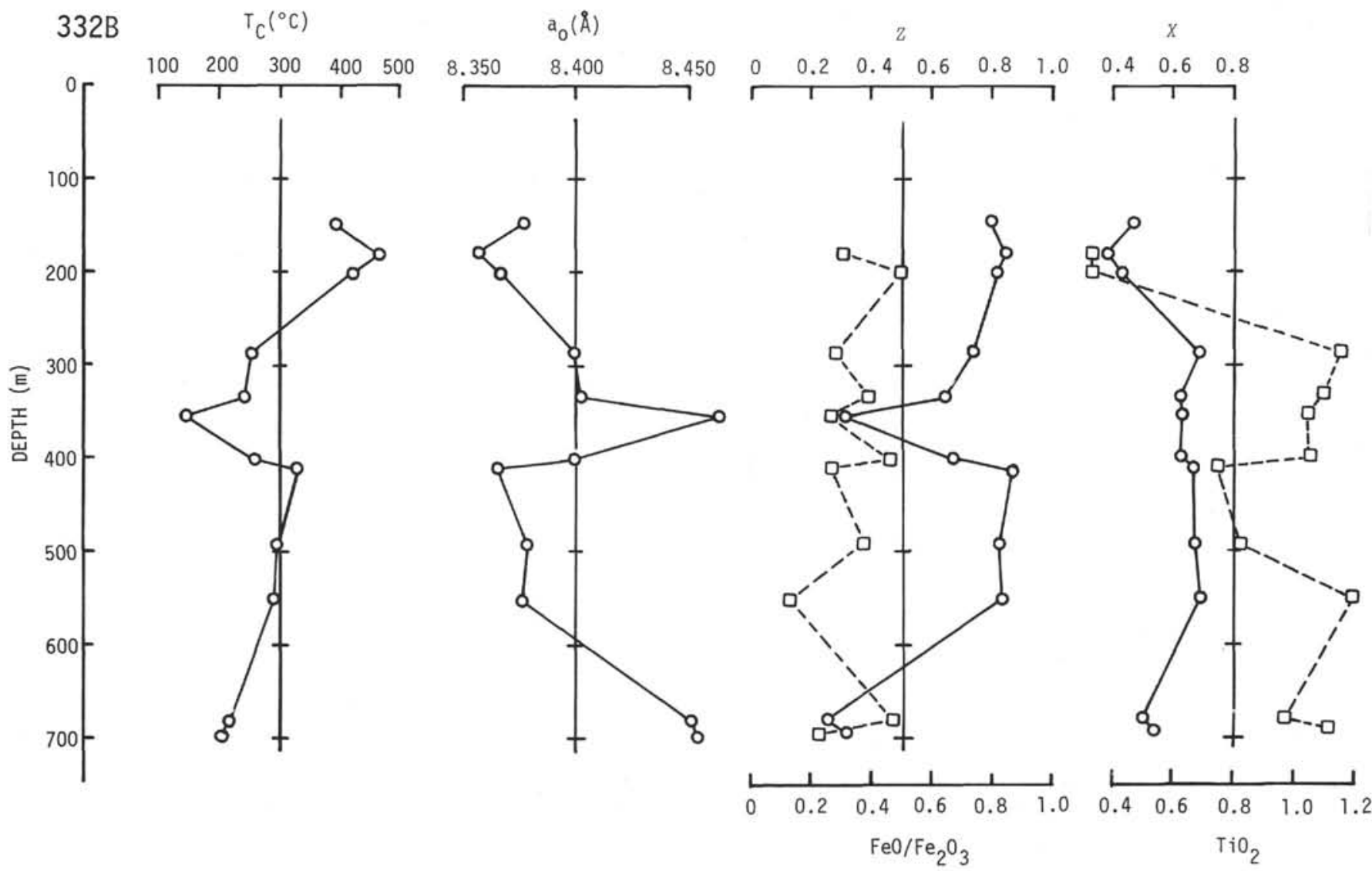

Figure 4b. Downhole variation of the Curie temperature and the lattice constant of the ferrimagnetic Fe-Ti spinel components, their oxidation parameter $\mathrm{z}$ together with the whole-rock $\mathrm{FeO} / \mathrm{Fe}_{2} \mathrm{O}_{3}$-ratio (dashed line) and the parameter $\mathrm{x}$ compared to the whole-rock titanium content ( $w t \%$, dashed line). The parameter $\mathrm{z}$ gives the proportion of $\mathrm{Fe}^{2+}$ oxidized to $\mathrm{Fe}^{3+}$ in titanomagnetites, while $\mathrm{x}$ gives their titanium content.

TABLE 2

Electron Microprobe Results, Ti-magnetite ${ }^{\mathrm{a}}$

\begin{tabular}{lrr|rr}
\hline & \multicolumn{2}{c|}{$332 \mathrm{~A}$} & \multicolumn{2}{c}{$332 \mathrm{~B}$} \\
& $29-1-9$ & $30-1-20$ & $10-3-2 \mathrm{~A}$ & $46-2-3 \mathrm{~B}$ \\
\hline $\mathrm{SiO}_{2}$ & 0.26 & 0.54 & 0.12 & 0.45 \\
$\mathrm{TiO}_{2}$ & 22.42 & 20.59 & 21.65 & 20.72 \\
$\mathrm{Al}_{2} \mathrm{O}_{3}$ & 1.98 & 2.32 & 1.73 & 1.82 \\
$\mathrm{Fe}_{2} \mathrm{O}_{3} \mathrm{~b}$ & 76.16 & 75.51 & 78.18 & 78.62 \\
$\mathrm{Cr}_{2} \mathrm{O}_{3}$ & 0.10 & 0.07 & 0.09 & - \\
$\mathrm{MnO}$ & 0.46 & 0.45 & - & 0.49 \\
$\mathrm{MgO}$ & 0.40 & 0.57 & 0.69 & 0.25 \\
$\mathrm{CaO}$ & 0.16 & 0.25 & 0.06 & 0.24 \\
$\mathrm{~K}_{2} \mathrm{O}$ & 0.01 & 0.02 & - & 0.01 \\
$\mathrm{Sum}$ & 101.95 & 100.32 & 102.52 & 102.60 \\
\hline
\end{tabular}

A Analysis: K. Abraham, Institut für Mineralogie, Ruhr-Universität Bochum, West Germany.

nature, the primary thermomagnetic magnetization being overprinted by other magnetization processes during later periods due to remagnetization, chemical magnetization, and viscous components:

1) There exists no correlation between NRM intensities and any of the other magnetic parameters measured so far, in particular saturation remanence, saturation magnetization, or magnetic stability. If the NRM is of a single type, any of these parameters should correlate as there is no great variation neither of the ore composition nor of the amount of opaque grains. Equivalent studies of the variation of magnetization within single lava flows and dikes show distinct correlations in most cases-for example, with saturation remanence (Watkins and Haggerty, 1967; Ade-Hall et al., 1968; Wilson et al., 1968; Petersen, 1976).

2) The carriers of remanent magnetization are very fine grained titanomaghemites. These cation-deficient spinels have been formed by low temperature oxidation (temperatures not exceeding $250^{\circ} \mathrm{C}$ ) of originally stoichiometric titanomagnetites. A recalculation of the initial Curie temperatures of these primary ore components (being the carrier of the original thermoremanence acquired during the initial cooling) yields a mean $T_{c i}$ of $119^{\circ} \mathrm{C}$ with $36 \%$ of the $T_{c i}$ values being below $60^{\circ} \mathrm{C}$. These low Curie temperatures make it likely that partial remagnetization may have taken place at only moderately elevated temperatures.

In regard to the acquisition of a chemical remanence, Marshall and Cox (1971) have shown that the direction of an original remanent magnetization of titanomagnetite is not destroyed by oxidation, if the oxidation occurs below the original Curie temperature of the titanomagnetite. On the other hand, Butler (1973) gives 

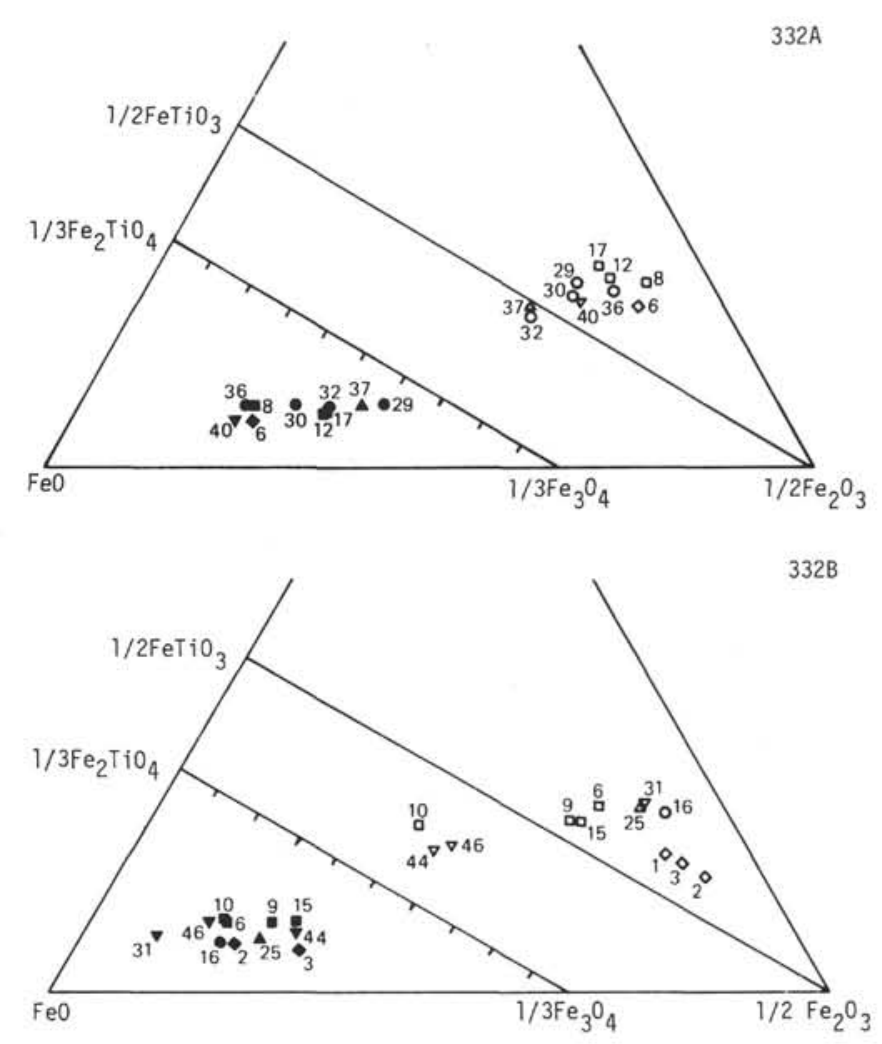

Figure 5. Composition of the ferrimagnetic ore components (open symbols) and the corresponding whole-rock compositions (full symbols) within the ternary system $\mathrm{FeO}-\mathrm{Fe}_{2} \mathrm{O}_{3}-\mathrm{TiO}_{2}$. Numbers refer to cores; different symbols to magma groups as defined by Flower et al. (this volume). (a) Hole 332A. (b) Hole 332B.

arguments that low-temperature oxidation of oceanic basalts will cause a significant portion of the originally stable carriers of the remanence to become superparamagnetic and thus lose their initial magnetization.

\section{ACKNOWLEDGMENTS}

This study is a combined contribution of the Institut fur Geophysik, Ruhr-Universität Bochum and the Institut für Geophysik, Universität Munchen. Prof. Dr. H. Baule and Prof. Dr. G. Angenheister generously made available the facilities of the above-named institutions.

We are grateful to the members of the shipboard party, Drs. P. Robinson and M. Flower, who provided the samples for investigations.

Many people have assisted us in the experimental work. To all these people we want to express our thanks, in particular to Dr. G. Schönharting, who also gave valuable contributions to the interpretation of data.

The financial support by the Deutsche Forschungsgemeinschaft is gratefully acknowledged.

\section{REFERENCES}

Ade-Hall, J.M., Khan, M.A., Dagley, P., and Wilson, R.L., 1968. A detailed opaque petrological and magnetic investigation of a single Tertiary lava from Skye, Scotland. I, II, III: Geophys. J., v. 16, p. 375-415.

Ade-Hall, J.M. and the Scientific Party DSDP Leg 37, 1975. Sources of magnetic anomalies on the Mid-Atlantic Ridge: Nature, v. 255, p. 389-390.
Bleil, U., 1976. An experimental study of the titanomagnetite solid solution series: Pageoph.

Butler, R.F., 1973. Single-domain to superparamagnetic transition during low-temperature oxidation of oceanic basalts: J. Geophys. Res., v. 78, p. 6868-6876.

Creer, K.M. and Petersen, N., 1969. Thermochemical magnetization in basalts: Z. Geophys., v. 35, p. 501-516.

Hargraves, R.B., and Petersen, N., 1971. Notes on the correlation between petrology and magnetic properties of basaltic rocks: Z. Geophys., v. 36, p. 29-37.

Hart, R.A., 1973. A model for chemical exchange in the basalt-seawater system of oceanic layer II: Canadian J. Earth Sci., v. 10, p. 799-816.

Lowrie, W., 1974. Oceanic basalt magnetic properties and the Vine and Matthews hypothesis: J. Geophys., v. 40, p. 513-536.

Lowrie, W., L $\phi$ vlie, R., and Opdyke, N.D., 1972. The magnetic properties of Deep Sea Drilling Project basalts from the Atlantic Ocean: Earth Planet. Sci. Lett., v. 17, p. 338-349.

Marshall, M. and Cox, A., 1971. Effect of oxidation on the natural remanent magnetization of titanomagnetite in suboceanic basalt: Nature, v. 40 , p. $28-31$.

1972. Magnetic changes in a pillow basalt due to sea floor weathering: J. Geophys. Res., v. 77, p. 64596469.

O'Reilly, W. and Banerjee, S.K., 1967. The mechanism of oxidation in titanomagnetites: a magnetic study: Min. Mag., v. 36 , p. $29-37$.

O'Reilly, W. and Readman, P.W., 1971. The preparation and unmixing of cation deficient titanomagnetites: $\mathbf{Z}$. Geophys., v. 37, p. 321-327.

Ozima, M., Joshima, M., and Kinoshita, H., 1974. Magnetic properties of submarine basalts and the implications on the structure of the oceanic crust: J. Geomag. Geoelectr., v. 26, p. $335-354$.

Petersen, N., 1976. Notes on the variation of magnetization within basalt lava flows and dykes: Pageoph.

Petersen, N. and Bleil, U., 1973. Self reversal of remanent magnetization in synthetic titanomagnetites: Z. Geophys., v. 39 , p. $965-977$.

Readman, P.W. and O'Reilly, W., 1970. The synthesis and inversion of nonstoichiometric titanomagnetites: Phys. Earth Planet. Inter., v. 4, p. 121-128.

Richards, J.C.W., O'Donovan, J.B., Hauptman, Z., O'Reilly, W., and Creer, K.M., 1973. A magnetic study of titanomagnetite substituted by magnesium and aluminum: Phys. Earth Planet. Inter., v. 7, p. 437-444.

Schaeffer, R.M. and Schwarz, E.J., 1970. The mid-Atlantic ridge near $45^{\circ} \mathrm{N}$ : IX. Thermomagnetics of dredged samples of igneous rocks: Canadian J. Earth Sci., v. 7, p. 268-273.

Schult, A., 1971. On the strength of exchange interactions in titanomagnetites and its relation to self-reversal of magnetization: Z. Geophys., v. 37, p. 357-365.

Talwani, M., Windisch, C.C., and Langseth, M.G., Jr., 1971. Reykjanes Ridge: A detailed geophysical study: J. Geophys. Res., v. 76, p. 473-517.

Watkins, N.D. and Haggerty, S.E., 1967. Primary oxidation variation and petrogenesis in a single lava: Contrib. Mineral. Petrol., v. 15, p. 251-271.

Wilson, R.L., Haggerty, S.E., and Watkins, N.D., 1968. Variation of palaeomagnetic stability and other parameters in a vertical traverse of a single Icelandic lava: Geophys. J., v. 16, p. 79-96.

Zijderfeld, J.D.A., 1966. A.C. demagnetization of rocks: analysis of results. In Collinson, D.W., Creer, K.M., and Runcorn, S.K. (Eds.), Methods in palaeomagnetism: Amsterdam (Elsevier), p. 254-286. 